\title{
Alan MacDiarmid, um Nobel, uma lição de vida!
}

Gostaríamos de compartilhar com a comunidade de polímeros o texto abaixo retirado da biografia do prof. Alan Graham MacDiarmid, premio Nobel de Quimica em 2000, o $4^{o}$ prêmio na área de polímeros, pela descoberta e desenvolvimento de plásticos que conduzem eletricidade, e que faleceu no ultimo 07 de fevereiro de 2007 em sua casa na Filadélfia, PA/USA.

\section{De Sua Biografia}

“...Shortly after learning of my being a recipient of the Nobel Prize I was speaking to one of my brothers in New Zealand by phone and I said how lucky I was to have been raised in a poor family which was also a close loving family. The fact that we were poor made us self reliant and conscious of the value of money. The fact that we were closely knit taught us the important aspets of interpersonal relationships. Everyone expects "the important things" in life that such as birthday and Christmas presents, but it is the "little unimportant" actions which actually are the real important things. These put the flesh on the skeleton of any relationship. Several hundred of these each week - the unimportant, the unexpected, the unnecessary, "the little things", are the things that really count. We are lucky to have been brought up in this environment, but there is a statement on the wall of my study at home in suburban Philadelphia which reads, "I am a very lucky person and the harder I work the luckier I seem to be"! It is my home life while growing up through high school, which I consider to have been the single most important factor in any success which I may have had in life. As my parents always said, "...an 'A's grade in a class is not a sign of success." Success is knowing that you have done your best and have exploited your God-given or genegiven abilities to the next maximum extent. More than this, no one can do...".

(Texto tirado de sua biografia do site: http://nobelprize. org/nobel_prizes/chemistry/laureates/2000/macdiarmidautobio.html, outras informações sobre ele e outros Nobels (Nobel Diploma, video da Aula Magna de recebimento do Nobel, galeria de fotos, etc) podem também ser encontradas neste site).

Quadro 1. Relação de prêmios Nobel em Polímeros.

\begin{tabular}{|c|c|c|c|}
\hline Nome & Nobel & Ano & Motivo do recebimento $^{1}$ \\
\hline Hermann Staudinger & Química & 1935 & "Por sua descoberta na química macromolecular" \\
\hline Karl Zigler e Giullio Natta & Química & 1963 & $\begin{array}{c}\text { "Por sua descoberta no campo da química e } \\
\text { tecnologia de altos polímeros." }\end{array}$ \\
\hline Paul Flory & Química & 1974 & $\begin{array}{l}\text { "Por sua fundamental conquista, ambas teóricas } \\
\text { experimenta, na físico-química de macromoléculas." }\end{array}$ \\
\hline $\begin{array}{l}\text { Alan G. MacDiarmid; Alan Heeger e } \\
\text { Hideki Shirakawa }\end{array}$ & Química & 2000 & $\begin{array}{l}\text { "Por sua descoberta e desenvolvimento dos plásticos que } \\
\text { conduzem eletricidade." }\end{array}$ \\
\hline
\end{tabular}

${ }^{1}$ Fonte: Pagina da Academia da Suécia.

\section{Sua formação}

A sua iniciação profissional começou em 1944, sendo assistente de laboratório do departamento de Quimica, no colégio universitário Victoria em Masterton, na Nova Zelândia, se formou em Quimica em 1948, na Universidade da Nova Zelandia, possuindo dois mestrados, um em 1950 na mesma universidade e outro em 1952 na Universidade de Wisconsin, bem com dois doutorados, em 1953 na mesma univer-
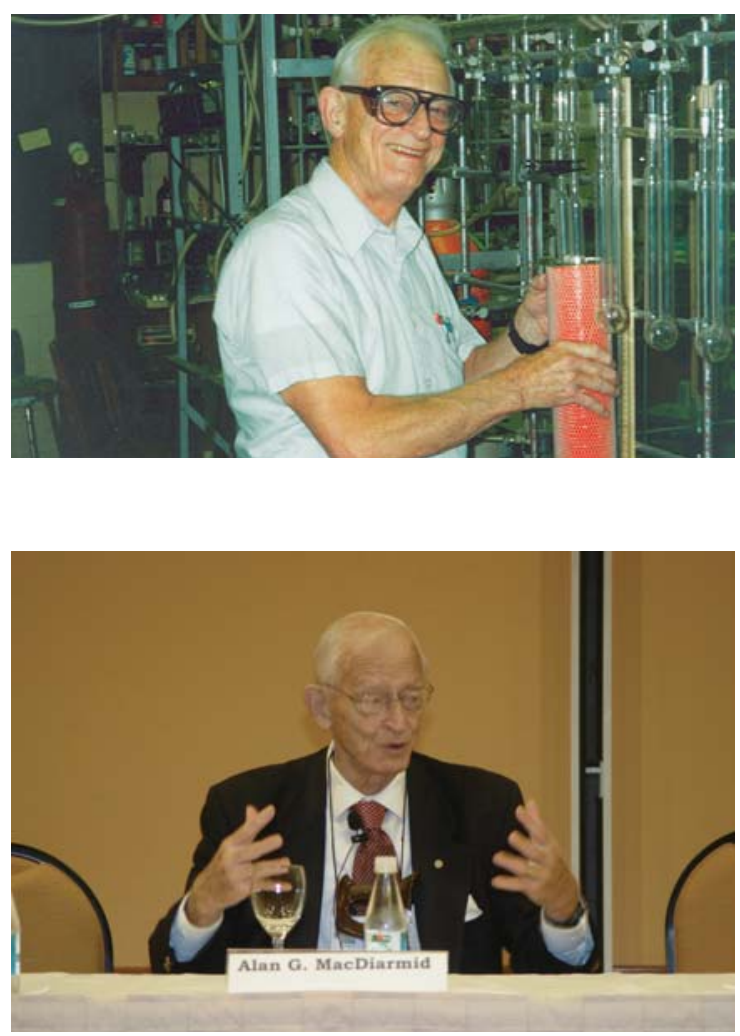


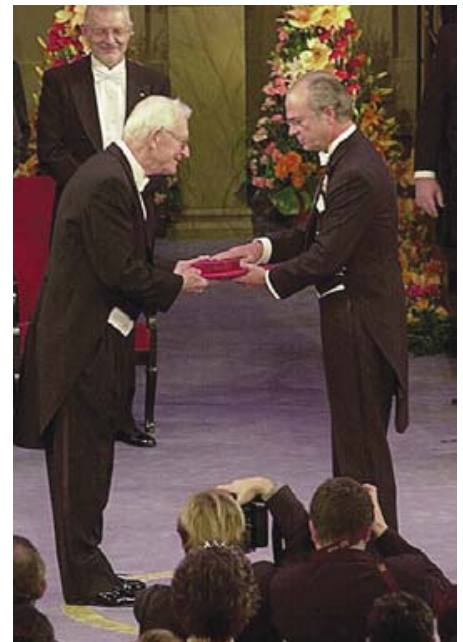

Prof. MacDiarmid (esquerda) recebendo seu Prêmio Nobel sidade de Wisconsin nos Estados Unidos e outro em 1955, na Unversidade de Cambrige na Inglaterra. O seu trabalho inicial foi na área de química inorgânica, como podemos ver em sua primeira publicação em 1949, com o artigo na importante revista Nature ("Preparation of Mono-Halogen Substituted Compounds of Sulphur Nitride", A.G. MacDiarmid, Nature, 1949, 1131). Porém ele sempre esteve disposto a aceitar novos desafios,

sem temer o inesperado, o que poderia simplesmente ser um erro experimentar, ou algo muito pequeno e desprezível, mas que o levou a mudar de área pois descobriu a possibilidade de condutividade elétrica em polímeros ("Synthesis of Electrically Conducting Organic Polymers: Halogen Derivatives of Polyacetylene $(\mathrm{CH}) x$, H. Shirakawa, E.J. Louis, A.G. MacDiarmid, C.K. Chiang and A.J. Heeger, J. Chem. Soc. Chem. Comm., 1977, 579) descoberta que lhe concedeu o premio Nobel junto com Hideki Shirakawa e Alan Heeger.

\section{Sua interação com a ABPol}

O prof. MacDiarmid visitou várias vezes o Brasil e nos honrou com sua participação em eventos da $\mathrm{ABPol}$, não somente pela possibilidade de viver um momento histórico dentro da área de polímeros, já que a última vez que esta área havia sido contemplada com um prêmio nobel havia sido em 1974, mas também por transmitir a todos um entusiasmo particularmente contagiante que demonstrava claramente sua paixão pela pesquisa, o que fez com que ele continuasse trabalhando até o final de sua vida. Sua última visita ao Brasil foi durante o MACRO/2006 no Rio, porém possuía um longo histórico de colaboração com pesquisadores do Brasil, o que levou ao lançamento em 2004 das bases do $6^{\circ}$ instituto Alan MacDiarmid do mundo, atualmente em construção na Embrapa Instrumentação Agropecuária de São Carlos. Os demais Institutos que levam seu nome estão localizados na China, Coréia, Índia, Nova Zelândia e Texas, nos Estados Unidos.

A comunidade de polímeros teve o prazer de interagir em várias oportunidades não só com um dos maiores cientistas de sua área, um prêmio Nobel, mas acima de tudo com um homem impressionante. Este texto, tirado de sua biografia, mostra muito bem um pouco disto. Antes de ser

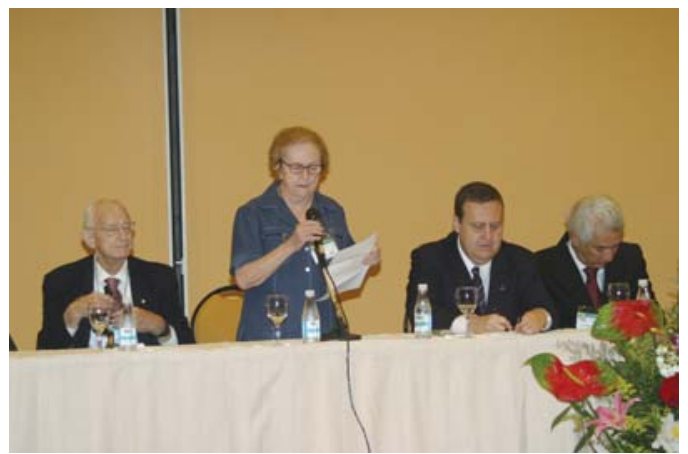

Prof. MacDiarmid na mesa de abertura do Macro 2006 ao lado da Prof ${ }^{\mathrm{a}}$ Eloisa Mano.

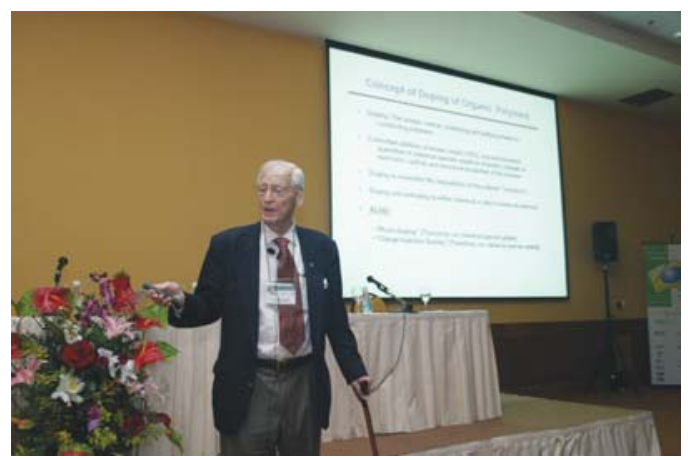

Apresentando sua palestra no Macro 2006.

um grande cientista ele era acima de tudo um ser humano fantástico que deixava muito claro a importância que dava para o lado humano de todas as pessoas com as quais ele encontrava e/ou colaborava, pela atenção, respeito, paciência e interesse que demonstrava pelo trabalho de cada um. Por outro lado sabia exigir o máximo das habilidades, que ele chamou como "God-given or gene-given" que cada um tem para dar, acreditando que somente assim, pode-se ter a satisfação de sentir que a nossa missão como profissional e ser humano está sendo cumprida. Após ser laureado com o Nobel ele passou a finalizar suas palestras com o lema: "Science is People", fazendo uma reflexão de que, a peça mais importante da ciência não são equipamentos e laboratórios ultra-avançados, mas acima de tudo: recursos humanos bem formados, dedicados e empenhados a colaborar e a dar o melhor de si. Deixa claro também o papel fundamental que a sua formação familiar e as dificuldades enfrentadas na vida desempenharam dando-lhe força e sabedoria para vencer obstáculos e desafios futuros. Que nós possamos lembrar do prof. MacDiarmid e aproveitarmos esta lição de vida que ele nos deixou, não esquecendo de prestar atenção em coisas que talvez hoje nós ainda consideramos "the little things", como ele dizia, mais que um dia poderão desempenhar um papel realmente chave na nossa vida pessoal e profissional.

Matéria elaborada por L. H. C. Mattoso e P. S. P. Herrmann 